\title{
Analysis of the environmental and productive performance of a lean supply chain through simulation scenarios
}

\author{
José Alfredo Jiménez 1,*, Salvador Hernández 1, Edgar Augusto Ruelas ${ }^{2}$, Roberto Baheza ${ }^{3}$, Pedro \\ Yáñez ${ }^{4}$, José Martín Medina ${ }^{5}$ and Sandra Téllez ${ }^{6}$, Vicente Figueroa ${ }^{1}$ \\ 1 National Technology of Mexico in Celaya, Department of Industrial Engineering; Av. García Cubas 1200, \\ Esquina Ignacio Borunda, Celaya, Gto. México. Tel: +52-461-611-7575; alfredo.jimenez@itcelaya.edu.mx (J. \\ A. J.); salvador.hernandez@itcelaya.edu.mx (S. H.), vicente.figueroa@itcelaya.edu.mx (V. F.) \\ 2 National Technology of Mexico in Irapuato, Department of Industrial Engineering, Carretera Irapuato - \\ Silao km 12.5 Colonia El Copal, Tel:. +52-462-606-7900, Irapuato, Guanajuato; edruelas@itesi.edu.mx \\ 3 University of Guanajuato at Department of Management Technologies Master Industrial Engineering, \\ Ph.D.. CIATEC, México.; r.baeza@ugto.mx \\ 4 Polytechnic University of Guanajuato, Metrology, Av. Universidad Sur 1001, Comunidad Juan Alonso, \\ 38483 Cortazar, Gto. México. Teléfono: +52-461-441-4300; pyanez@upgto.edu.mx \\ 5 National Technology of Mexico in Celaya, Department of Mechanical Engineering; Av. García Cubas 1200, \\ Esquina Ignacio Borunda, Celaya, Gto. México. Tel.: +52-461-611-7575; martin.medina@itcelaya.edu.mx \\ 5 Polytechnic University of Guanajuato, Logistic, Av. Universidad Sur 1001, Comunidad Juan Alonso, 38483 \\ Cortazar, Gto. México. Tel.: +52-461-441-4300; stellez@upgto.edu.mx \\ * Correspondence: Alfredo.jimenez@itcelaya.edu.mx; Tel.: +52-461-327-5880
}

\begin{abstract}
This article aims to serve as a guide for the construction of supply chain simulation models designed with a lean approach, using Promodel software. To achieve this, a supply chain was designed for a fictitious company located in the City of Celaya, Guanajuato and a set of suppliers located in different cities within the same State. It was used as a google tool to define the distances between each of the companies. As a final result, a representative model of a supply chain was obtained, as well as a methodology that allows the construction of lean supply chains regardless of the number of companies that comprise it. The effect of the variability in the delivery times between suppliers was incorporated into the simulation model, as well as an equation that calculates the pollution emissions of the vehicles that integrate the network that moves the products between the companies. With this work it is possible to represent networks of supply chains of real world companies, where the variability and contamination factor is included, to facilitate the decision making regarding the number of vehicles, inventory levels, quantities to be shipped, frequency in the shipments, etc. with the purpose of contaminating as little as possible and at the same time preventing interruptions in the supply chain using the least amount of resources possible.
\end{abstract}

Keywords: Supply chains; simulation model; contamination

\section{Introduction}

The increase of the competitiveness in all the industrial sectors due to the globalization of the economies is a source of pressure so that the companies must optimize their processes; the foregoing also generates new forms of collaboration between companies that are part of the supply chain. To achieve this, techniques and information technologies are needed to support decision-making; One of these tools is the simulation of systems. The simulation models allow analysis of the type What happens if ...?, To evaluate and quantify the benefits derived from the collaboration of all companies in the supply chain [1].

Ramanathan in [2] proposed a simulation model to understand the performance of a supply chain; This highlights the importance of collaboration between companies that belong to the chain. 
Chatfield in [3] developed a simulator for the integration of the operation of the supply chain; generating a robust and flexible tool that allows to design and analyze supply chain models. This tool measures five important characteristics of the models: the storage model, the architecture of the system, the ease of use, the depth of the model and the characteristics of the outputs.

A supply chain faces changes that contribute to increasing its complexity and vulnerability to shocks; a supply chain must resist changes in the environment to survive. Through the simulation alternative supply chains can be evaluated to improve the capacity of recovery to a disturbance [4]. There are numerous simulation models built for the design, evaluation and optimization of the supply chain [5].

Discrete events simulation is a widely used approach as a support tool in logistics and for the analysis of supply chains since it is a tool that allows to emulate the behavior of this kind of systems [6]. It should be noted that in the supply chains the factor that is always taken into consideration in the design phases is the transportation of the goods; there are three ways to transport goods: land transport, air transport and maritime transport.

Based on the above, an 18-step methodology is proposed that facilitates the construction and analysis of supply chain models; and that helps professionals make decisions; the methodology is based on the Promodel package.

Mexico is seeking to establish a global leadership in relation to the care of the environment. Recently it has committed to establish 2026 as the peak year of its greenhouse gas (GHG) emissions; as of that year, said emissions should be reduced.

The Mexican government has proposed a road map which has been described as a "detailed climate change plan that is the first of its kind among developing nations" [7].

At a global level, the fight against climate change has become one of the main topics of international debate [8]. As an example, the following pair of reports is mentioned: Young, Min, young and Jinsoo in [9] measured the $\mathrm{CO}_{2}$ emissions that are generated internationally due to globalization; on the other hand, Yee et al., in [10] made a detailed analysis of greenhouse gas emissions due to the transport of goods; focusing mainly on the measurement of $\mathrm{CO}_{2}$. It should be noted that this article considers the $\mathrm{CO}_{2}$ measurement of the supply chain and also; to achieve an optimal design; tools such as lean manufacturing, simulation and design of experiments are applied.

In this document, the design of experiments is applied to identify the factors that significantly affect the response variables as well as to define the optimal operating conditions [11]; in our case, the aim is to reduce delivery time, reduce inventory levels, reduce $\mathrm{CO}_{2}$ pollution rates and reduce the percentage of leisure in companies due to untimely delivery.

Finally, it should be mentioned that variability is considered within the analysis; this factor is presented in a supply chain in the cycle times of every company in its process [12].

\section{Model description}

According to García in [13], few people dedicate themselves to the art of modeling systems because it is not an easy subject to understand; in this work a simple but valuable system is proposed for the generation of ideas on how to simulate a slender supply chain with an ecological approach.

Consider a supply chain composed of 5 companies located in different cities of the State of Guanajuato, Mexico (Table 1). Each company was assigned a number from 1 to 5; each company has a geographical location. Table 1 also shows the part numbers that enter and leave each company, the cycle time to produce a single piece and the company to which they will allocate their product. 
Table 1. Supply chain description.

\begin{tabular}{|c|c|c|c|c|c|}
\hline $\mathrm{i}$ & City & Assembly description & Part & Cycle time & Customer \\
\hline 1 & Celaya & M0005, Sub 2 & End product & 1 min & Final client \\
\hline 2 & Salamanca & M0001 & M0001 & 2 min & Company 1 \\
\hline 3 & Irapuato & M0002, Sub 1 & Sub 2 & 1.5 min & Company 1 \\
\hline 4 & Silao & M0003, & Sub 1 & 2.5 min & Company 3 \\
\hline 5 & León & M0004 & M0004 & 1 min & Company 4 \\
\hline
\end{tabular}

This section may be divided by subheadings. It should provide a concise and precise description of the experimental results, their interpretation as well as the experimental conclusions that can be drawn.

To facilitate the analysis, Google maps were used to calculate the distances between the cities; however, in a real case, the geographical position of each company must be exactly located.

According to the data in Table 1, the supply chain operates as follows: Company 5 located in León city processes and supplies part number M0004 to company 4 located in Silao city. In company 4 the part number M0003 and the part number M0004 are assembled to form sub 1. Part Sub 1 is sent to company 3 located in Irapuato city; there the number of part M0002 is taken and it is assembled with the sub 1; the result is the sub 2 assembly that is sent to company 1 located in Celaya city. In company 2 the part number M0001 is processed and sent to company 1 . In company 1 the part number M0005 is taken and assembled with M0001 and Sub 2 to form a product as desired by the final consumer.

Figure 1 shows the supply chain with its companies, the material that enters and leaves each company and the flow that each of the products in the supply chain follows until the finished product is obtained and delivered to the consumer.

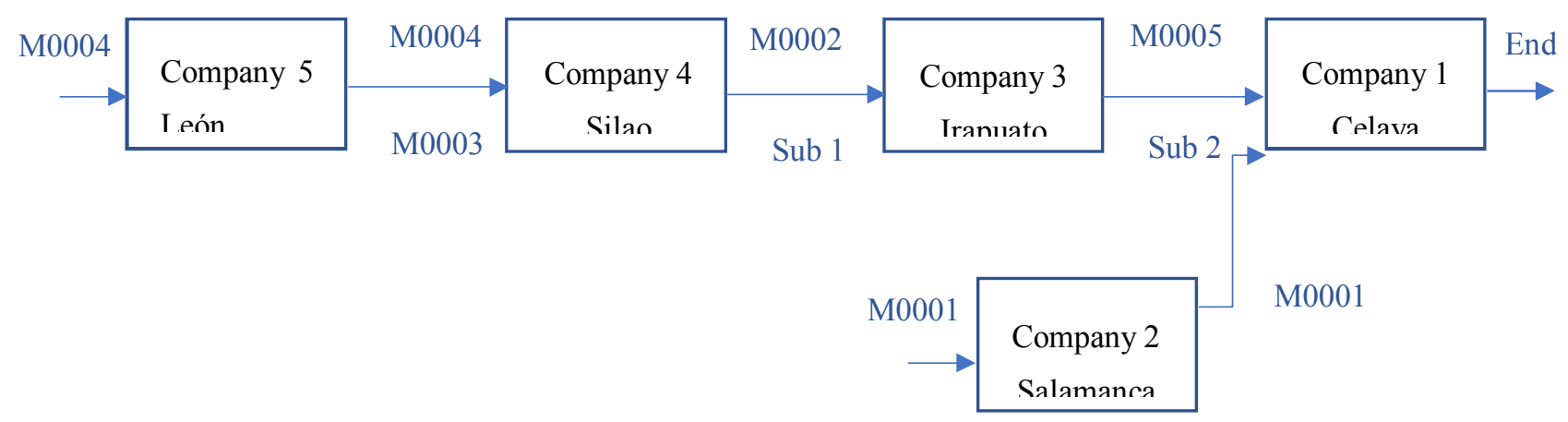

Figure 1. The supply chain and its inputs and outputs.

\section{Materials and Methods}

In this section we propose a methodology of 18 steps for the construction of simulation models of supply chains to obtain measures of productive and environmental performance; this methodology was applied to the system proposed in the previous section; it should be noted that this methodology can be applied to any supply chain regardless of its size. Below are the steps using the proposed example:

1. Identify the companies that are part of the supply chain and collect data.

In this case, there are 5 companies located in the cities of Celaya, Salamanca, Irapuato, Silao and León. The necessary data are: number of part that supplies each company, batch sizes of the shipments, frequency of the shipments, cycle time for the elaboration of the individual products, time in making the shipment, speed of the transport vehicle full and empty, material download time. 
139

140

141

142

143

144

145

2. Use a map to geographically locate each of the companies.

The map of the State of Guanajuato was downloaded and added to the Promodel figures library. To use the image, Promodel has a tool called Graphic Editor. The sequence to load the map is Tool - Graphic Editor. Copy and paste the image in the layout of the graphic editor. Close the graphic editor; when the software asks if you want to save the changes, select accept. The map or image will be available as an icon in the model (Figure 2).

146

147

148

149

150

151

152

153

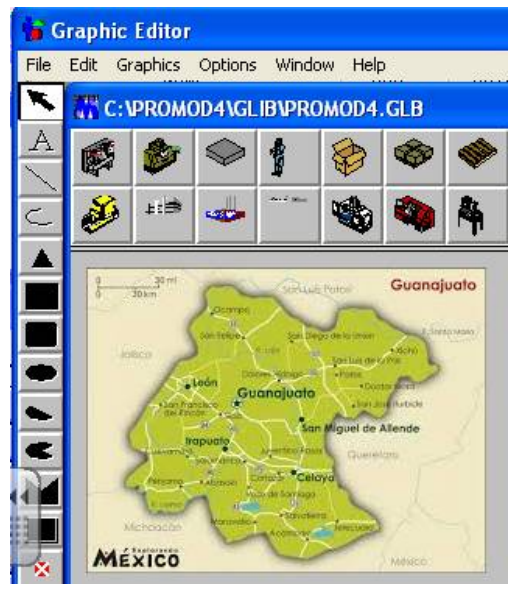

Figure 2. Graphic editor.

3. Use the map image in the layout, declare as background figure.

Use the map image in the layout, declare as background figure. The sequence is: Build Background of graphics - Behind of grid. (Figure 3)

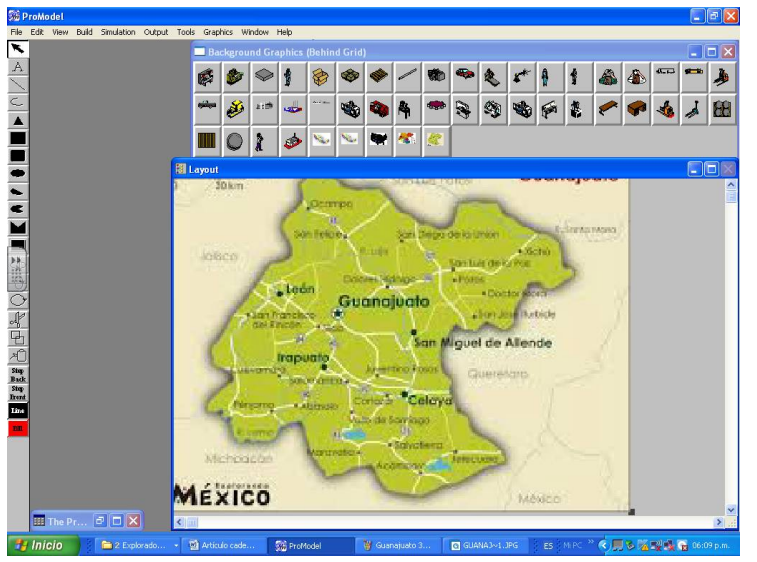

Figure 3. Example with the map of the State of Guanajuato, México.

4. Define the level of each company in the chain: tier 1, tier 2, tier 3,..., tier $n$.

For the developed example, companies 2 and 3 correspond to Tier 1, Company 4 is Tier 2 and Company 5 corresponds to Tier 3.

5. Define the sequence of the flow of materials through companies from tier $\mathrm{n}$ to tier 1 .

In Figure 1, the sequence of flow of materials through the chain is clearly seen from the previous section.

6. Determine the distances between each of the companies that make up the supply chain and build a network.

It is recommended to use Google maps. 
166

167

168

169

170

171

172

173

174

175

176

177

178

179

180

181

182

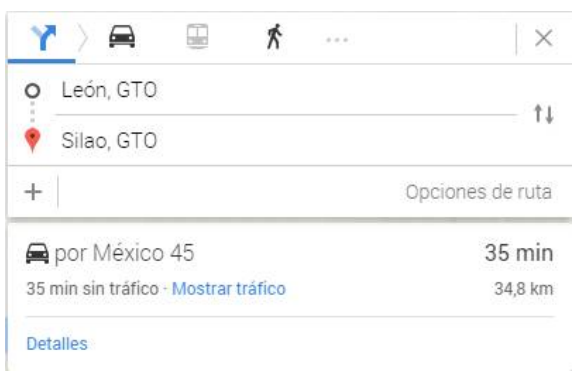

Figure 4. Defining distances in Promodel.

Figure 4 shows the example of how to calculate the distance between the city of León Gto. and Silao Gto., where the calculated distance is $34.8 \mathrm{~km}$.

Table 2 shows the summary of the distances between the cities involved in the supply chain.

Table 2. Distance between locations.

\begin{tabular}{|c|c|c|}
\hline Source & Target & Distance $(\mathrm{KM})$ \\
\hline León & Silao & 34.8 \\
\hline Silao & Irapuato & 37.1 \\
\hline Irapuato & Celaya & 64.1 \\
\hline Salamanca & Celaya & 43.7 \\
\hline
\end{tabular}

7. Define the locations.

Each location corresponds to a company. The locations must be declared on the map loaded in step 3. The locations will represent each of the companies in the supply chain. Each company will have a warehouse of raw material to allow the arrival of raw materials from its suppliers; and a warehouse of finished product to temporarily store the final product until the quantity requested by the client is met and then the shipment is made. Figure 5 shows the companies and stores of each company.

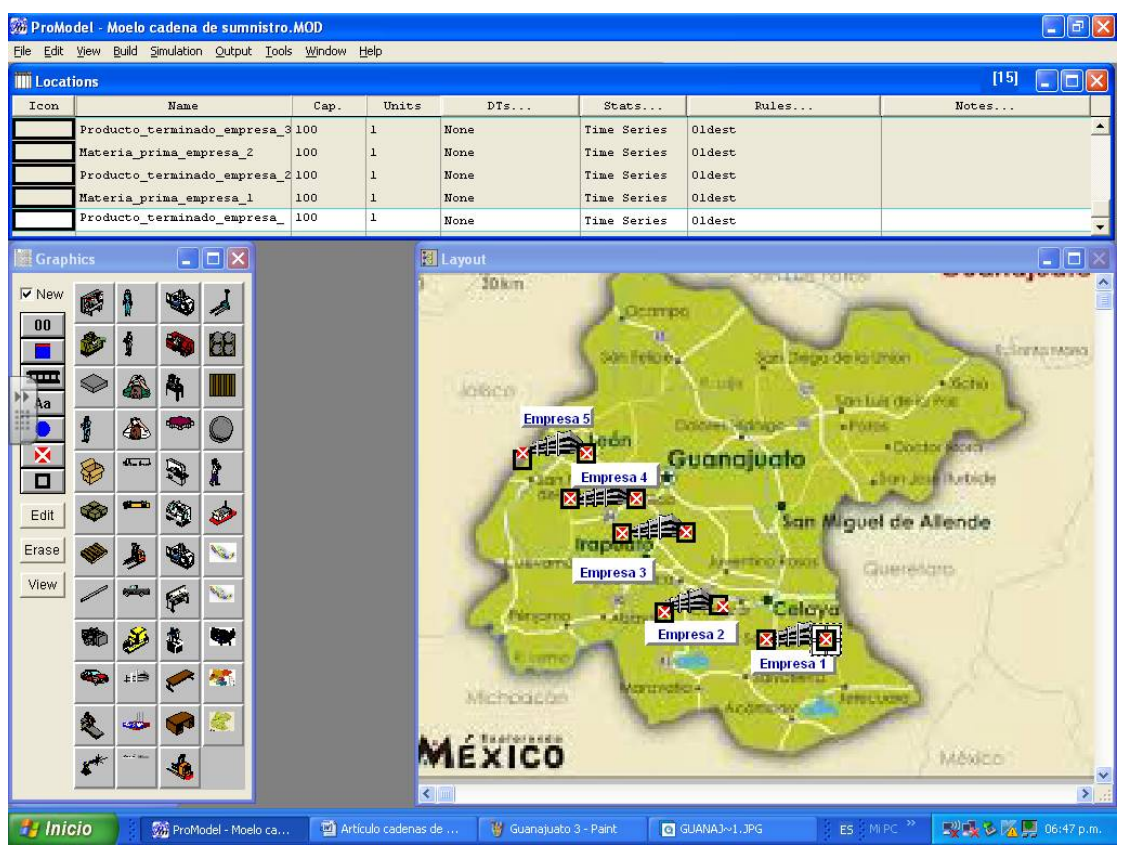

Figure 5. Location of the cities on the map. 
186

187

188

189

190

191

192

193

194

195

196

197

198

199

200

201

202

203

204

205

206

207

208

209

210

211

212

213

214

215

216

217

218

219

220

221

222

223

224

225

226

227

228

229

230

231

232

233

234

235

236

237

8. Define the entities that will move through the supply chain.

In the example, there are 8 entities, enough to exemplify the design of a supply chain consisting of 5 companies. The entities are: M0001, M0002, M0003, M0004, M0005, Sub 1, Sub 2 and Final product.

9. Define the arrivals.

It is assumed that each company already has raw materials in its warehouses. Since each company already has its raw material (M0001, M0002, M0003, M0004, M0005); only arrivals must be declared for entities M0001 to M0005. Otherwise, one more link in the supply chain that would correspond to the supplier of the companies should be declared.

10. Define the process according to the sequence followed by the materials, from company 5 to company 1.

To build simulation models, basic software knowledge is required.

11. Define the network. The network represents the road where the truck moves.

The lengths of the segments between nodes represent the distance between cities, for this example the distances are taken from Table 2. To define "meters" as the unit of distance measurement, the following sequence is followed in Promodel: Build - General Information - meters. For example, the distance between the cities of León and Silao is $34.8 \mathrm{~km}$; in Promodel you must enter 34800 meters. When defining the network, the interfaces must also be declared; It is recommended that these be from each of the nodes to the stores of entry and exit of each company. In total there will be 5 nodes, one for each company.

12. Define the resource (truck).

A resource called a truck was defined, which will be responsible for transporting the materials from one company to another. Part of the experimentation consists in evaluating the number of trucks required. In the resource the user must specify the network through which the resource must move. In this case a network called "truck network" was declared. In addition, it is necessary to specify the speeds of the resource; for this example, it is assumed that a full truck moves at a speed of $80 \mathrm{~km} / \mathrm{hr}$; however, the software requires that the speed be entered in meters per minute $(\mathrm{mpm})$, therefore a speed of $1333 \mathrm{mpm}$ was specified; the speed when traveling empty was set at $95 \mathrm{~km} / \mathrm{hr}$ or $1583 \mathrm{mpm}$. The time for the loading operation of a truck was set at 10 minutes and to unload it was set at 15 minutes; the model requires the times in seconds: 600 and 900 seconds respectively. In the experimentation, the variability of loading and unloading times was included; later, the three levels considered are shown.

13. Verify the model.

First, a visual inspection of the operation of the model was carried out by executing a test run. You must ensure that the movements of the truck follow a logical sequence, trucks with material must arrive at their destination to make the delivery in the entry locations of each company; the finished products of each company must be picked up by the trucks at the collection points and must be delivered to the company to which it supplies.

14. Validate the model.

There are different ways to validate a model; the most advisable is to compare the statistics of the real data against the statistics of the outputs of the simulation model. Nevertheless, in this example, the test is omitted for the moment given that it is an illustrative example.

15. Determine the stabilization period (warm up).

In this case it is assumed that the steady state is reached when the first batch of finished product comes out. The stabilization period is different for each case of batch size to be produced.

16. Experiment.

The application of the experimental design methodology is proposed; the variables are: the size of the lots to be transported, the number of trucks to be used and the variability; with respect to the lots, sizes of 20, 40 and 80 pieces were defined; for trucks the levels are 1, 2 or 3 trucks; for the variability three levels were defined: low, moderate and high. In total there are three variables with three levels each, so we have a design 33. To solve the problem of degrees of freedom for the error, two replicas are proposed per run. In total there are 27 treatments that replicate twice, 
resulting in 54 experimental runs. The response variables are: the $\mathrm{CO}_{2}$ pollution indexes, the completion time of a batch requested by a customer, the level of performance of the trucks and the inventory levels in each company.

To determine $\mathrm{CO}_{2}$ emissions, it was considered a practical guide for the calculation of greenhouse gas (GHG) emissions. March 2011 version, proposed by the Interdepartmental Commission on Climate Change [14]. The automotive vehicle proposed for this investigation is the Ford vehicle, sub-brand Transit, version 2/4/5 doors, model 2018, manual transmission, diesel, 4 cylinders, with a power of $125 \mathrm{HP}$, a 2.2 Liter engine.

So that in the final results of each experimental run, the Promodel software was capable of throwing $\mathrm{CO}_{2}$ measurements, it was necessary to enter 6 variables, the first 5 serve to control the number of trips made from one plant to another and from this way to calculate the total distance covered by the entire fleet, as observed in equation 1 .

DIST TOTAL $=(34.8 \times$ DIST 1$)+(37.1 \times$ DIST 2$)+(64.1 \times$ DIST 3$)+(43.7 \times$ DIST 4$)$,

Where:

DIST TOTAL $=$ Total distance covered by the entire fleet

DIST $1=$ Number of trips from León to Silao

DIST $2=$ Number of trips from Silao to Irapuato

DIST $3=$ Number of trips from Irapuato to Celaya

DIST $4=$ Number of trips from Salamanca to Celaya

The sixth variable was used to calculate the $\mathrm{CO}_{2}$ emitted. For this purpose, the information provided by the government of Mexico was used in the link www.ecovehículos.gob.mx, where it is possible to determine the $\mathrm{CO}_{2}$ emitted by any vehicle and vehicle model. In this case, according to the vehicle proposed in this article, there is a $\mathrm{CO}_{2}$ emission of $270 \mathrm{gr} / \mathrm{Km}$.

According to the above, the variable $\mathrm{CO}_{2}$ that is programmed in the Promodel software is stable through equation 2. $\mathrm{CO} 2=[(270 \mathrm{xDISTTOTAL}) \mathrm{X} 2] / 1000$

Where:

$\mathrm{CO} 2=$ Emission of $\mathrm{CO} 2$, by trucks and all trips made, in kilograms.

The reason to multiply by 2 the product of DIST TOTAL and 270, is to consider when the vehicles return empty. The division between 1000 is because the final result of CO2 will be expressed in kilograms instead of grams.

17. Document results.

The results of all the experimental runs were recorded and analyzed in detail in the following section entitled analysis of results.

18. Determine the best conditions of the supply chain and obtain the conclusions.

Based on the results observed and the detailed analysis, the conditions of the supply chain that optimize the response variables defined are established. The details of this step are presented in the following section.

\section{Results}

The model was constructed according to the steps suggested in the methodology, it was run according to the experiments proposed, where 54 experimental runs were found. In the model, the different factors were included, such as lot size: lots of size 20, 40 and 80 ; the number of trucks: 1, 2 and 3 trucks and the level of variation: low, medium and high. To consider the effect of the variation, it was established that the average cycle times of the processes of each of the companies are distributed according to a normal distribution with the average time and standard deviation, as shown in Table 3. 
Table 3. Distance between locations.

\begin{tabular}{|c|c|c|c|c|c|}
\hline \multirow{2}{*}{$\mathrm{i}$} & \multirow{2}{*}{ City } & \multirow{2}{*}{ Cycle time } & \multicolumn{3}{|c|}{ Cycle time with Variation } \\
\cline { 4 - 6 } & & & Low & Half & High \\
\hline 1 & Celaya & $1 \mathrm{~min}$ & $\mathrm{~N}(1,0.5)$ & $\mathrm{N}(1,1)$ & $\mathrm{N}(1,2)$ \\
\hline 2 & Salamanca & $2 \mathrm{~min}$ & $\mathrm{~N}(2,0.5)$ & $\mathrm{N}(2,1)$ & $\mathrm{N}(2,2)$ \\
\hline 3 & Irapuato & $1.5 \mathrm{~min}$ & $\mathrm{~N}(1.5,0.5)$ & $\mathrm{N}(1.5,1)$ & $\mathrm{N}(1.5,2)$ \\
\hline 4 & Silao & $2.5 \mathrm{~min}$ & $\mathrm{~N}(2.5,0.5)$ & $\mathrm{N}(2.5,1)$ & $\mathrm{N}(2.5,2)$ \\
\hline 5 & León & $1 \mathrm{~min}$ & $\mathrm{~N}(1,0.5)$ & $\mathrm{N}(1,1)$ & $\mathrm{N}(1,2)$ \\
\hline
\end{tabular}

In accordance with the above, the results shown in Table 4 were obtained. The model was run until the production of a batch of 80 pieces was achieved, assuming that this is the amount required

Table 4. Results of the 54 runs.

\begin{tabular}{|c|c|c|c|c|c|c|c|}
\hline \multirow{2}{*}{ Run } & \multicolumn{3}{|c|}{ Factors } & \multicolumn{4}{|c|}{ response variable } \\
\hline & Lot Size & Trucks & Variation & $\mathrm{CO}_{2}(\mathrm{Kg})$ & $\mathrm{LT}(\mathrm{Hr})$ & $\%$ Idle Trucks & Invetorv level \\
\hline 1 & 20 & 1 & Low & 115.28 & 20.28 & 1.79 & 113.19 \\
\hline 2 & 20 & 1 & Half & 109.42 & 21.56 & 1.92 & 119.43 \\
\hline 3 & 20 & 1 & High & 117.54 & 20.57 & 2.73 & 116.17 \\
\hline 4 & 20 & 2 & Low & 165.35 & 7.24 & 5.02 & 90.97 \\
\hline 5 & 20 & 2 & Half & 150.37 & 7.59 & 9.74 & 96.06 \\
\hline 6 & 20 & 2 & High & 141.23 & 8.33 & 10.29 & 100.96 \\
\hline 7 & 20 & 3 & Low & 210.57 & 4.6 & 28.78 & 60.49 \\
\hline 8 & 20 & 3 & Half & 209.86 & 4.8 & 31.56 & 79.51 \\
\hline 9 & 20 & 3 & High & 232.84 & 5.3 & 36.61 & 74.26 \\
\hline 10 & 40 & 1 & Low & 64.71 & 7.68 & 8.93 & 105.12 \\
\hline 11 & 40 & 1 & Half & 56.89 & 9 & 8.44 & 117.5 \\
\hline 12 & 40 & 1 & High & 60.07 & 9.59 & 12.66 & 116.82 \\
\hline 13 & 40 & 2 & Low & 93.49 & 4.57 & 54.88 & 83.18 \\
\hline 14 & 40 & 2 & Half & 94.62 & 4.92 & 56.10 & 82.79 \\
\hline 15 & 40 & 2 & High & 87.11 & 5.6 & 57.31 & 88.42 \\
\hline 16 & 40 & 3 & Low & 98.57 & 3.94 & 65.26 & 73.71 \\
\hline 17 & 40 & 3 & Half & 94.10 & 4.07 & 65.9 & 75.86 \\
\hline 18 & 40 & 3 & High & 79.21 & 4.76 & 69.59 & 88.42 \\
\hline 19 & 80 & 1 & Low & 18.97 & 6.99 & 54.73 & 111.13 \\
\hline 20 & 80 & 1 & Half & 19.84 & 7.31 & 56.76 & 110.83 \\
\hline 21 & 80 & 1 & High & 21.87 & 8.62 & 63.31 & 110.16 \\
\hline 22 & 80 & 2 & Low & 21.08 & 6.29 & 80.41 & 105.71 \\
\hline 23 & 80 & 2 & Half & 21.93 & 6.61 & 81.38 & 105.63 \\
\hline 24 & 80 & 2 & High & 23.8 & 7.92 & 84.45 & 105.71 \\
\hline 25 & 80 & 3 & Low & 21.08 & 6.29 & 86.94 & 105.71 \\
\hline 26 & 80 & 3 & Half & 21.93 & 6.61 & 87.58 & 105.71 \\
\hline 27 & 80 & 3 & High & 23.8 & 7.92 & 89.63 & 105.63 \\
\hline 28 & 20 & 1 & Low & 107.93 & 21.46 & 1.44 & 117.64 \\
\hline 29 & 20 & 1 & Half & 114.02 & 20.22 & 1.41 & 115.14 \\
\hline 30 & 20 & 1 & High & 127.14 & 21.2 & 1.46 & 121.76 \\
\hline 31 & 20 & 2 & Low & 146.4 & 7.17 & 11.59 & 93.86 \\
\hline 32 & 20 & 2 & Half & 132.87 & 7.40 & 7.53 & 98.85 \\
\hline 33 & 20 & 2 & High & 179.29 & 8.01 & 14.34 & 93.73 \\
\hline 34 & 20 & 3 & Low & 212.06 & 4.82 & 28.78 & 77.04 \\
\hline 35 & 20 & 3 & Half & 232.36 & 4.44 & 31.83 & 81 \\
\hline 36 & 20 & 3 & High & 192.11 & 5.07 & 30.32 & 88.1 \\
\hline 37 & 40 & 1 & Low & 55.09 & 8.93 & 7.37 & 117.97 \\
\hline 38 & 40 & 1 & Half & 64.14 & 7.66 & 8.65 & 105.95 \\
\hline 39 & 40 & 1 & High & 55.41 & 9.51 & 10.85 & 120.4 \\
\hline 40 & 40 & 2 & Low & 87.97 & 4.66 & 53.07 & 86.45 \\
\hline 41 & 40 & 2 & Half & 86.33 & 4.34 & 55.48 & 85.3 \\
\hline 42 & 40 & 2 & High & 82.43 & 5.08 & 56.08 & 89.78 \\
\hline
\end{tabular}




\begin{tabular}{|l|l|l|l|c|c|c|c|} 
& 40 & 3 & Low & 94.89 & 4.01 & 65.04 & 75.34 \\
\hline 43 & 40 & 3 & Half & 101.13 & 3.72 & 66.17 & 72.74 \\
\hline 45 & 40 & 3 & High & 89.41 & 4.47 & 68 & 89.79 \\
\hline 46 & 80 & 1 & Low & 101.13 & 7.07 & 55.30 & 112.3 \\
\hline 47 & 80 & 1 & Half & 18.58 & 7.08 & 55.37 & 111.04 \\
\hline 48 & 80 & 1 & High & 19.69 & 8.42 & 62.44 & 112.14 \\
\hline 49 & 80 & 2 & Low & 19.83 & 6.39 & 80.68 & 107.6 \\
\hline 50 & 80 & 2 & Half & 20.63 & 6.39 & 80.71 & 105.68 \\
\hline 51 & 80 & 2 & High & 22.54 & 7.35 & 85.74 & 107.06 \\
\hline 52 & 80 & 3 & Low & 19.83 & 6.37 & 87.12 & 107.6 \\
\hline 53 & 80 & 3 & Half & 20.61 & 6.39 & 87.14 & \\
\hline 54 & 80 & 3 & High & 22.54 & 7.35 & 90.49 & 105.71 \\
\hline
\end{tabular}

The results of the runs were introduced to the Minitab 17 software to perform the statistical analysis of the experiments through the analysis of variance (ANOVA). Before presenting the ANOVA for each of the response variables, an analysis is presented of the assumptions that must be met for residuals such as normality, constant variance and independence [15], which can be seen in

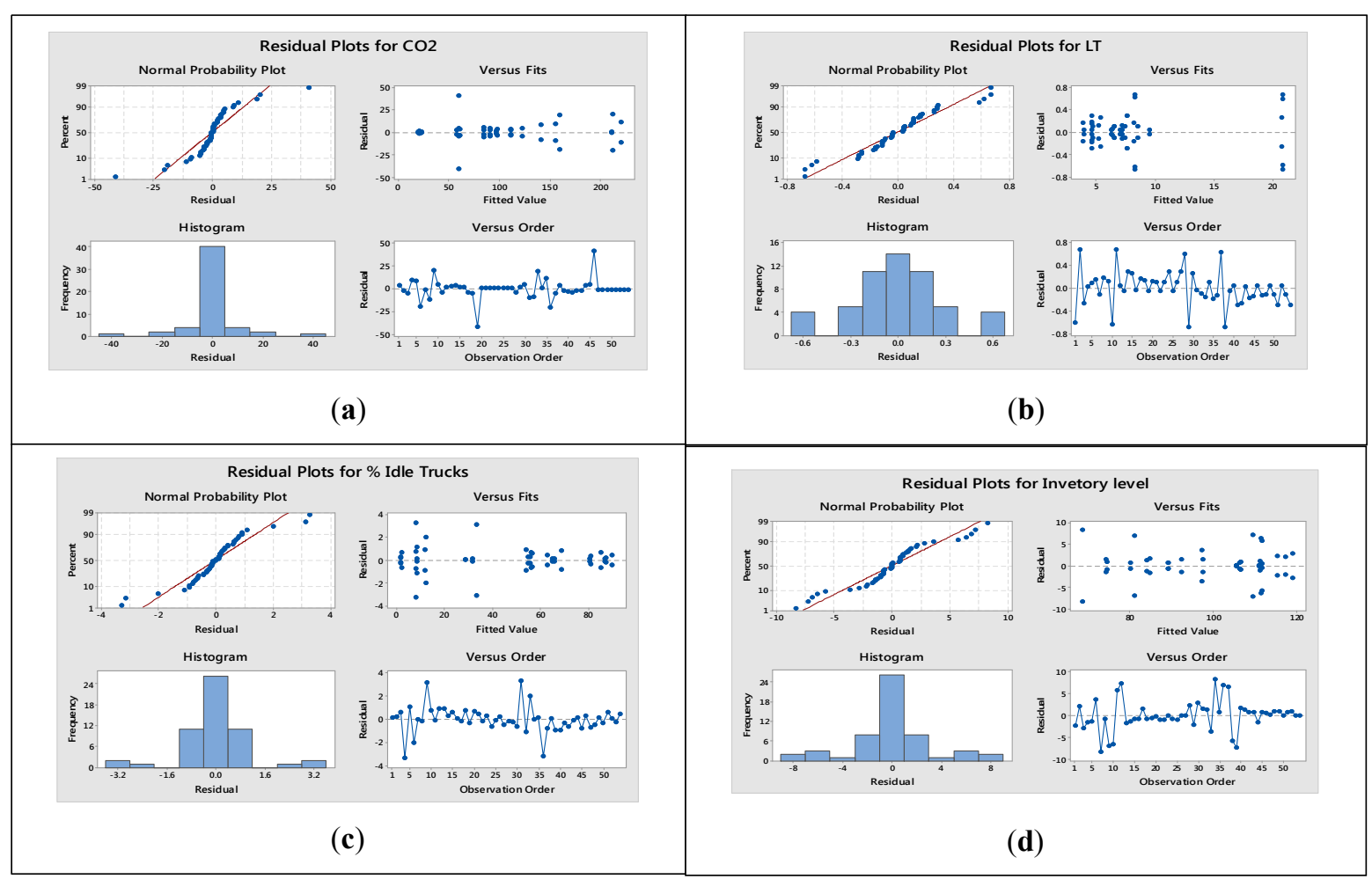

Figure 6. Verification of assumptions.

In each of the figures 6 (a) to 6 (d) it can be seen in the upper left corner that the blue points (Residuals) approach the red diagonal line, with which it can be concluded that the assumption of Normality is met. You can also observe the fulfillment of this assumption through each of the histograms. The assumption of constant variance can be verified by observing the figure located in the upper right corner, where it can be seen that the residuals do not have a funnel shape. Finally, in the lower right corner it can be seen that the order of the residuals has a completely random behavior, so the assumption of independence is also fulfilled.

Once the assumptions have been verified, the next step is to study each of the ANOVAS to determine which factors have a significant effect on the response variable. The first ANOVA observed in Figure 7 corresponds to the $\mathrm{CO}_{2}$ response variable. 


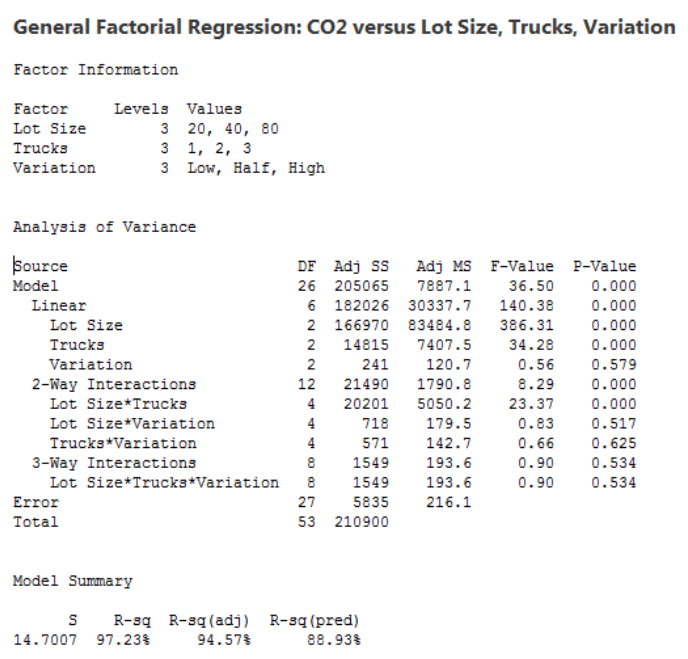

Figure 7. ANOVA $\mathrm{CO}_{2}$.

In Figure 7, it can be seen that the lot size and number of trucks has a significant effect on the pollution index $\left(\mathrm{CO}_{2}\right)$ since its $\mathrm{p}$-value is less than 0.05 . This means that depending on the number of trucks used to move materials between companies and the size of the lot moving between companies, they will cause the $\mathrm{CO}_{2}$ that is emitted to the environment to increase or decrease. Later, an analysis will be carried out to determine the appropriate number of trucks and lot size, to minimize the contamination index. It can also be observed that the variation factor does not have a significant effect on $\mathrm{CO}_{2}$ since its $\mathrm{p}$-value is greater than 0.05 , which means that the variability in processing times in each of the companies does not have an important effect in the $\mathrm{CO}^{2}$ pollution indexes. Finally, it can be seen that of the effects of double or triple interaction, the only one that siginicatively affects $\mathrm{CO}_{2}$ is the interaction of lot size and number of trucks. An interesting value obtained is the coefficient of determination $\left(\mathrm{R}^{2}\right)$, which is $97.23 \%$, which indicates that the model explains $97.23 \%$ of the variability observed.

Regarding the lead time variable, the respective ANOVA can be seen in Figure 8.

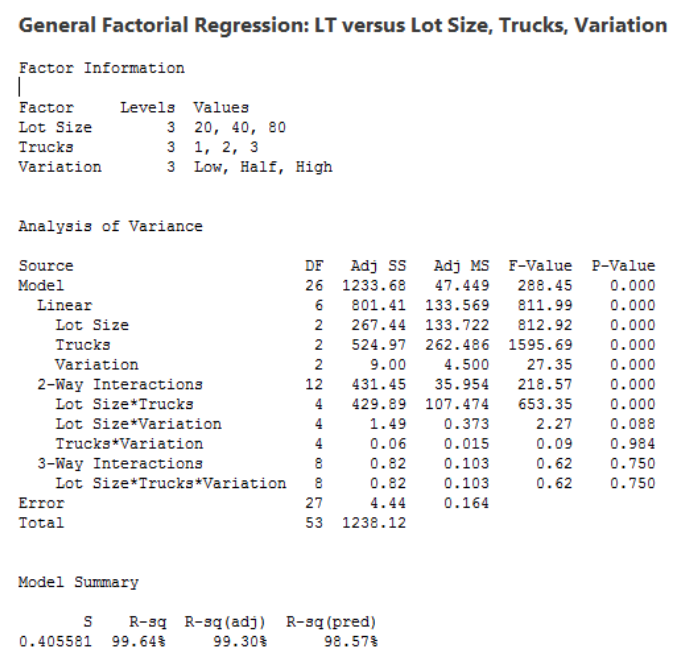

Figure 8. ANOVA LT.

In Figure 8, it can be seen that the three main factors have a significant effect on the lead time (LT) since their p-value is less than 0.05 . This means that depending on the number of trucks, the lot size that moves between companies and the variability of each of the companies, will be the lead time of the batch of 80 pieces to the final customer. From the effects of double or triple interaction, it can 
363

364

365

366

367

368

369

370

371

372

373

374

375

376

377

378

379

380

381

be seen that only the interaction between the lot size and the number of trucks is significant. According to the $\mathrm{R}^{2}$, we have that $99.64 \%$ of the variability is explained by the model, which means that the model is able to predict almost perfectly.

The ANOVA for the response variable percentage of idle of trucks can be seen in Figure 9.

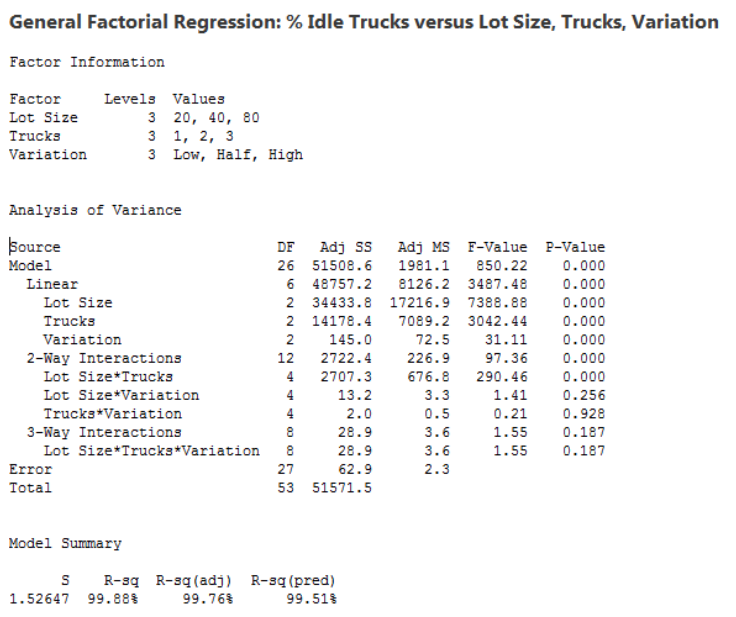

Figure 9. ANOVA \% Idle of the turcks.

In Figure 9, it can be seen that the three factors, lot size, number of trucks and variation in processing times in the companies, have a significant effect on the \% idle, response variable of the trucks, since their $\mathrm{p}$-value is less than 0.05 . This means that the idle percentage of the trucks can be increased or decreased depending on the number of trucks that are used, the size of the batch moving between companies and the variability observed in the processes of each company. Of the effects of double or triple interaction, it is appreciated that only the double effect between lot size and number of trucks, has a significant effect on the lead time variable, the rest, does not have a significant effect since its p-value is greater than 0.05 . In relation to $\mathrm{R}^{2}$, we have that $99.88 \%$ of the variability is explained by the model.

Finally, in Figure 10, you can see the ANOVA for the inventory level response variable

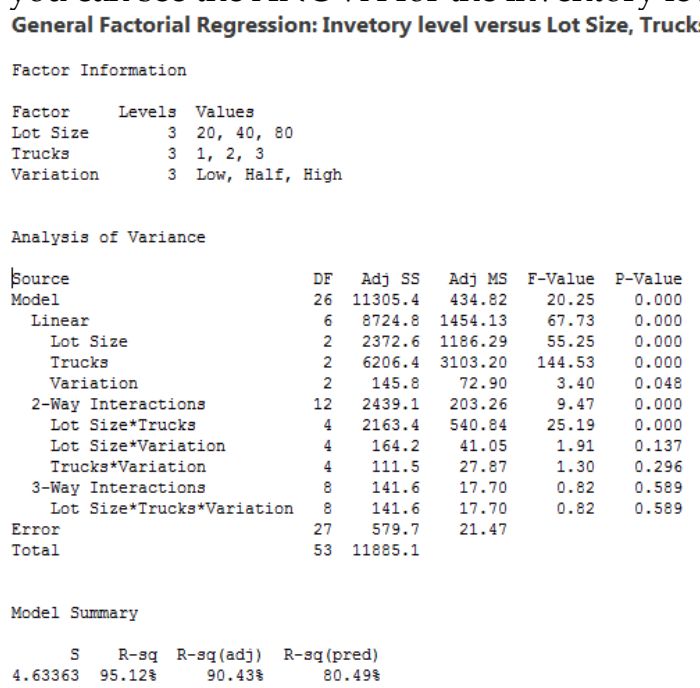

Figure 10. ANOVA \% Inventory level.

In Figure 10, it can be observed that the three factors, lot size, number of trucks and variation in the processing times in the companies, has a significant effect on the response variable level of inventory, since its $\mathrm{p}$-value is less than 0.05 . This means that the inventory level can be increased or decreased depending on the number of trucks that are used, the size of the batch moving between companies and the variability observed in the processes of each company. It should be mentioned 
389

390

391

392

393

394

395

396

397

398

399

400

401

402

403

404

405

406

407

408

409

410

that the p-value of the variability factor was very close to the critical region, since its value was 0.048 , which means that it significantly affects the inventory level variable, but it does so to a lesser extent than the size of lot and number of trucks. Regarding the effects of double or triple interaction, it is seen that only the double effect between lot size and number of trucks, has a significant effect on the level of inventory, the rest, does not have a significant effect since its $p$ value is greater than 0.05 . In relation to $\mathrm{R}^{2}$, we have that $95.12 \%$ of the variability is explained by the model.

The previous analysis in the ANOVAS, serves to determine which factors can affect each of the response variables defined in this research to then determine the level that each of the factors must operate in order to operate the system or supply chain in the most efficient way possible. In this sense, the optimizer of the response variables included in the Minitab 17 software was used. Accordingly, a criterion must be defined for each response variable, such as between larger better, nominal is better or smaller better. For example, pollution is a quality feature whose increase is undesirable, so it would seek to minimize, so it is a variable between smaller better. Delivery time is a very important feature in a supply chain, whose high values cause breaks in the chains, so you always want to minimize its value, therefore it has the smallest best feature. With regard to the idle of trucks, according to the principles of lean thinking, you want to use the least amount of resources, so that idle is desirable to reduce it. Its characteristic is for this reason, the smaller the better. Finally, for the inventory level response variable, according to the lean manufacturing philosophy, inventories represent high waste that must be reduced, for this reason it has a smaller better characteristic and it is necessary to minimize it.

Once the above was clarified, the optimizer of the response variables included in Minitab 17 was used, as shown in Figure 11.

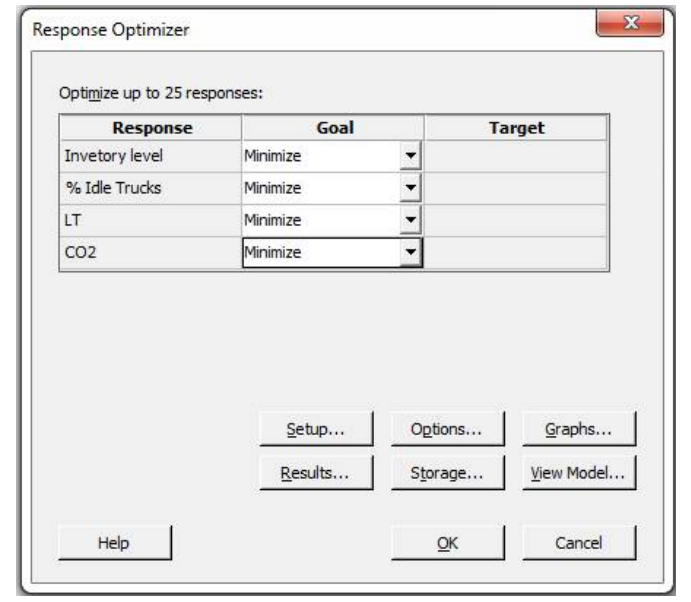

Figure 11. Response optimizer.

After the previous step, the result observed in Figure 12 was obtained.

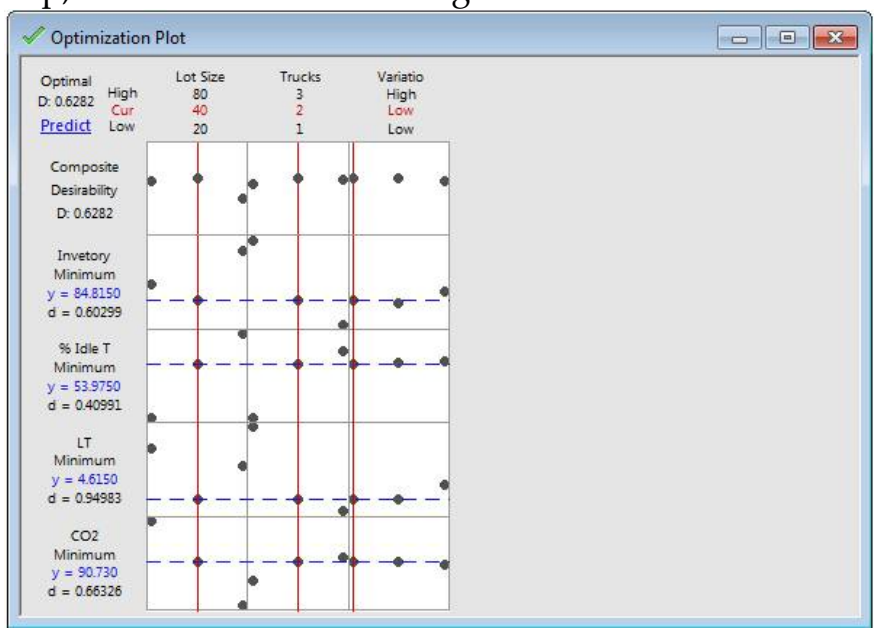

Figure 12. Optimal response. 
According to the result shown by the optimizer, it can be seen that the lot size that must be moved between companies is 40 pieces, 2 trucks must be used for the movement of materials and, as expected, the level of variation in the Process times of the companies, should be at the lowest possible. When establishing the system according to the optimal response, we have the following average answers: Global inventory level, 85 pieces; idle percentage of the entire truck fleet that moves materials between companies, $54 \%$; Average lead time, since the material arrives at the first company until the batch of 80 finished pieces is delivered to the final customer, 4.62 hours and finally; 90.73 kilograms of $\mathrm{CO}_{2}$ emitted by the entire truck fleet to be able to move all the necessary materials between companies to produce a batch of 80 pieces for the final customer.

\section{Discussion}

The design of supply chains under a lean and environmental approach is necessary to achieve the objectives of each of the companies that comprise it. In this epoch, it is not only important to worry about the efficiency of the supply chain in terms of economic profitability, but also to think in environmental terms, for this reason it is proposed to integrate several tools, in this article we propose lean manufacturing, simulation and design of experiments. As future research it is proposed to apply the steps suggested in this methodology of construction of supply chains to a real case and document it. Add in the variability factor real data of process times by performing a goodness-of-fit test in the first instance, to determine which is the true probability distribution that the data follow. In addition, other response variables can be added that measure the economic and environmental impact by reducing the $\mathrm{CO}_{2}$ levels of the supply chain.

\section{Conclusions}

In this article we have presented a novel methodology to design supply chains with a lean and ecological approach, based on simulation scenarios and design of experiments. The methodology for a group of fictitious companies was developed, however, it is perfectly applicable for companies that are part of a real-world supply chain. It can be used as software to simulate the Promodel, or any other software that facilitates the discrete event simulation. In this case, the $\mathrm{CO}_{2}$ pollution index, the lead time, the idle percentage of the trucks and the inventory level were considered as response variables, however, the methodology is not limiting and more response variables can be added, depending on of the needs of the company. Likewise, it is possible to add more factors to be analyzed that could affect the response variables, for example, capacities of cargo trucks, type of engine, truck brand, etc. It is proposed as future research to apply the methodology to a real case and document it.

Author Contributions: José Alfredo Jiménez carried out the construction of the simulation model representative of a supply chain and analyzed the results of the simulation scenarios. Salvador Hernández collaborated with the translation and revised the whole paper. Edgar Augusto Ruelas and Roberto Baheza carried out the design of experiments. José Martín Medina proposed the way to measure $\mathrm{CO}_{2}$ and proposed the equation to introduce it as a variable to Promodel software. Sandra Téllez and Vicente Figueroa designed the fictitious supply chain. Pedro Yáñez revised the results of the design of the experiments.

Funding: This research received funding from the National Technological Institute of Mexico in Celaya, the authors thank all the support received.

Acknowledgments: This work was supported by the National Technological Institute of Mexico in Celaya, Project No. 89u5f0 (4204).

Conflicts of Interest: The authors declare no conflict of interest. 
464

465

466

467

468

469

470

471

472

473

474

475

476

477

478

479

480

481

482

483

484

485

486

487

488

489

490

491

492

493

494

495

496

497

498

499

500

501

502

503

504

\section{References}

1. Terzi, S.; Cavalieri S. Simulation in the supply chain context: a survey. Computers in Industry 2004, 53, 3-16. DOI: 10.1016/S0166-3615(03)00104-0

2. Ramanathan, U. Performance of Supply Chain Collaboration-A Simulation Study. Expert Systems with Applications 2014, 41, 210-220. http://dx.doi.org/10.1016/j.eswa.2013.07.022

3. Dean C.; Chatfield; Terry P. H.; Jack C.; Hayya SISCO: An object-oriented supply chain simulation system Decision Support Systems 2006 42(1):422-434. https://doi.org/10.1016/j.dss.2005.02.002

4. Carvalho, H.; Ana, P.; Machado, V.; Acevedo, S.; Macado, V. Supply Chain redesign for resilience using simulation. Computers and industrial engineering 2012. Vol. (62) pp 329 - 341. https://doi.org/10.1016/j.cie.2011.10.003

5. Young H. L.; Sook H. K. Production-distribution planning in supply chain considering capacity constraints. Computers \& Industrial Engineering 2002. Volume 43, Issues 1-2, 1 Pages 169-190. doi.org/10.1016/S0360-8352(02)00063-3

6. Antuela A. T.; Stewart R. The application of discrete event simulation and system dynamics in the logistics and supply chain context. Decision Support Systems 2012. Volume 52, Issue 4, Pages 802-815. doi.org/10.1016/j.dss.2011.11.015

7. Freeman, L. México marca un hito con su promesa de reducir la contaminación de gases de efecto invernadero. Scientific American 2015, Tomado de ClimateWire con autorización de Environment \& Energy Publishing, LLC. www.eenews.net, 202-628-6500

8. Montoya, T. J.; Gutiérrez, F. E.; Blanco, E. Conceptual framework for measuring carbon footprint. Production Planning \& Control 2014, 37-41. DOI: 10.1080/09537287.2014.894215

9. Young, H., Min, K., Seo, J., Yun, B. Supply chain simulation with discrete - continous combined modeling. Computers and industrial engineering 2002. Vol. (43) pp 375 - 392. 2002. doi.org/10.1016/S0360-8352(02)000803

10. Yee, V. F.; Simon, P. Jiří, J. K.; Chew, T. L. A review on air emissions assessment: Transportation. Journal of Cleaner Production 2018. Volume 194, 1 Pages 673-684 doi.org/10.1016/j.jclepro.2018.05.151 [10]

11. Montgomery, D. C. Diseño y análisis de experimentos 2nd ed.;. Limusa Wiley. México 2005. ISBN 968-186156-6

12. Taho, Y.; Yiyo, K.; Chao, T. S.; Chia, L. H. (2015). Lean production system design for fishing net manufacturing using lean principles and simulation optimization. Journal of Manufacturing Systems 2015, Volume 34, Pages 66-73 doi.org/10.1016/j.jmsy.2014.11.010

13. Eduardo, G. D.; Heriberto, G. R.; Leopoldo, E. C. Simulación y análisis de sistemas con Promodel. 2nd ed.; Pearson, México 2013. ISBN 978-607-32-1511-4

14. Guía práctica para el cálculo de emisiones de gases de efecto invernadero (GEI). Versión Marzo 2011. Comisión interdepartamental de cambio climático. Catalunya, España.

15. Humberto, G. P.; Román, V. S. Análisis y diseño de experimentos, 2nd ed.;. Mc Grw Hill México, ISBN-10: 970-10-6526-3 